\title{
Profile of the Paraoxonase 1 (PON1) Gene 192Q/R Polymorphism and Clinical Associations among Older Singaporean Chinese with Alzheimer's and Mixed Dementia
}

\author{
Dennis C.C. Seow ${ }^{a}$ Qi Gao ${ }^{b, c}$ Philip Yap ${ }^{\text {e Jia Min Gan }}{ }^{d}$ \\ Hui Ling Chionh ${ }^{f}$ Su Chi Limg ${ }^{g}$ Lei Feng ${ }^{b, c}$ Tze Pin Ng ${ }^{b, c}$ \\ ${ }^{a}$ Geriatric Medicine, Singapore General Hospital, SingHealth, ${ }^{b}$ Gerontological Research \\ Programme, Yong Loo Lin School of Medicine, National University of Singapore, \\ 'Department of Psychological Medicine, National University Health System, ${ }^{d}$ Institute of \\ Medical Biology, A*STAR/Singapore OncoGenome Laboratory, and ${ }^{\mathrm{e}}$ Geriatric Medicine,

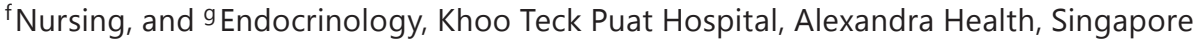

\section{Key Words}

Paraoxonase 1 - Alzheimer's disease - Mixed dementia - Singaporean Chinese elderly · Neuropsychiatric symptoms

\section{Abstract}

Background: To examine the prevalence of the Paraoxonase1 (PON1) gene 192Q/R polymorphism amongst Singaporean Chinese with Alzheimer's disease $(A D)$ and mixed dementia and possible clinical associations. Methods: We examined the presence of the PON1 192Q/R polymorphism together with cognitive status, functional status and neuropsychiatric symptoms among 186 older Singaporean Chinese with AD $(n=109)$ and mixed dementia $(n=77)$. $\boldsymbol{R e}$ sults: The $\mathrm{R}$ allele predominated in $67 \%$ of the $A D$ patients and $63.1 \%$ of the patients with mixed dementia. Within the mixed dementia subgroup, the $\mathrm{R}$ allele was significantly associated with a higher BADLS score, NPI-Q scores and CDR scores. Conclusion: Among older Singaporean Chinese with $A D$ and mixed dementia, the $R$ allele was predominant. In particular, within the mixed dementia subgroup, the $\mathrm{R}$ allele carrier status was associated with poorer functional status, greater presence of neuropsychiatric symptoms and a more severe stage of dementia. Further studies should be conducted. 
Seow et al.: PON1 Gene 192Q/R Polymorphism and Clinical Associations among Older

Singaporean Chinese with Alzheimer's and Mixed Dementia

\section{Introduction}

Singapore is a multiracial South-East Asian country with a rapidly ageing population. Together with the greying of the nation, the numbers of persons with dementia (PWD) is increasing from an estimated 53,000 by 2020 to 187,000 by 2050 . Amongst the older population, late onset Alzheimer's disease (AD) and vascular dementia (VaD) are the predominant forms of dementia. In a community study of older Singaporeans ( $>70$ years), the prevalence of possible $\mathrm{AD}$ was 60\%; while in a younger age group (50-69 years), the prevalence of possible VaD was $65 \%$ [1]. Mixed dementia as a diagnostic entity consisting primarily of $A D$ with the presence of stroke disease is also frequently observed in the local memory clinics [2]. Neuropsychiatric symptoms are frequently observed in about $60-75 \%$ of all PWD, most commonly apathy (27-36\%), depression (24-32\%) and agitation/aggression (24-30\%) [3, 4]. They pose enormous burdens of care, but remain less understood in terms of pathogenesis, risk factors and clinical course.

\section{The Paraoxonase Family}

The paraoxonase (PON) enzyme family comprises three members, PON1, PON2 and PON3, whose genes are located adjacent to each other on chromosome 7q21-22 [5]. In vivo, the PONs are involved in the reduction of oxidative stress and the prevention of atherosclerosis. PON polymorphisms with decreased levels of PON activity have thus been associated with vascular diseases including coronary artery disease and stroke [6-12]. PON2 is expressed in nearly all human tissues and exerts its anti-oxidative properties through the reduction of reactive oxygen species, low density lipoprotein (LDL) protection from oxidative stress and the enhanced anti-oxidant capacity of high density lipoprotein (HDL) [13]. PON3 is less studied but has been shown to reduce LDL oxidative stress with protection against atherosclerosis, although the specific natural substrates of PON3 have not been well characterized [13].

\section{Paraoxonase 1}

Of the 3 PONs, PON1 has been most intensely studied in relation to the risk of cardiovascular disease, stroke, oxidative stress and inflammation. Its encoding gene has also been identified as a longevity gene [14]. PON1 is synthesized in the liver and circulates on the surface of HDL particles, and it is a $\mathrm{Ca}^{2+}$-linked enzyme [15]. It was first studied for its organophosphatase activity which explained its ability to detoxify organophosphate through hydrolysis and thus provide neuroprotection against the effects of environmental neurotoxins and age-related neurodegeneration $[16,17]$. Subsequently, PON1 was ascribed to have significant anti-oxidative and anti-inflammatory properties through its enzymatic actions as a lactonase, peroxidase and esterase [13]. These properties account for the ability of HDL to prevent LDL oxidation.

\section{The PON1 192Q/R Polymorphism and Dementia}

PON1 also has cholinesterase-inhibitive properties. Human serum PON1 levels and activity display an up to 40 -fold interindividual variability and are genetically associated with a single nucleotide polymorphism (SNP) in the PON1 gene. PON1 polymorphisms include those in the coding (L55M; rs854560 and R192Q; rs662) and promoter region (-107A/G; rs705379 and -161C/T; rs705381) of the gene [18]. Of these, the molecular basis of the PON1 192Q/R gene polymorphism is a glycine (Gln) $\rightarrow$ arginine (Arg) substitution at residue 192 (NCBI database dbSNP: rs662) that results in three possible genotypes: QQ, QR and RR. The PON1 192Q/R polymorphism is of particular interest in AD because of its possible effects on dementia pathophysiology and response to cholinesterase inhibition [19]. In terms of activity based on genotyping, individuals carrying Arg at residue 192 (R allele) reportedly have a higher PON1-hydrolyzing activity than those carrying Gln (Q allele) [20]. Pola et al. [21] (in 
Seow et al.: PON1 Gene 192Q/R Polymorphism and Clinical Associations among Older

Singaporean Chinese with Alzheimer's and Mixed Dementia

2005) demonstrated that subjects carrying the R allele were more likely to respond to cholinesterase inhibitor therapy. As an endogenous cholinesterase inhibitor, PON1 may thus augment the biological activity of cholinesterase inhibitor drugs, thus improving their efficacy.

Regarding the association between dementia and PON1 192Q/R, clinical research has produced mixed results. A recent meta-analysis of 10 studies on AD patients showed no significant association of the PON1 192Q/R polymorphism on AD susceptibility [22]. To date, 11 case-control studies have observed the relationship between the PON1 polymorphism at 192Q/R and the risk of developing AD or dementia with inconsistent results. Only 2 of 8 studies in which AD patients were selected as cases reported a protective effect of the PON1 192Q/R polymorphism on the risk of developing AD [23, 24], and the other 6 studies showed a lack of association [19, 25-29]. For $\mathrm{AD}$ and $\mathrm{VaD}$, an earlier study reported low serum levels of PON1 in AD compared to VaD patients [30]. In three other studies which looked into both $A D$ and VaD patients, one showed that PON 192Q/R was not significantly associated with AD or $\mathrm{VaD}$, one found no significant difference, and one suggested that the $\mathrm{R}$ allele was an independent risk factor for $\mathrm{VaD}$ and mixed dementia [31-33]. Furthermore, no previous studies of patients with $\mathrm{AD}$ and $\mathrm{VaD}$ have examined the effect of the PON1 genetic polymorphism on the clinical manifestations and severity of dementia.

\section{Aims of the Study}

The primary aim of our study was to examine the profile of the PON1 gene and its 192Q/R polymorphism amongst PWD attending a Memory disorders clinicin Singapore. The secondary aim was to examine the possible associations of the 192Q/R polymorphism with cognition, physical function and neuropsychiatric symptoms. At the time of the study conception, due to limited resources, the $192 \mathrm{Q} / \mathrm{R}$ polymorphism was chosen to be studied as there was no local data on its profile among PWD.

\section{Methods}

\section{Subjects}

A cross-sectional study using convenience sampling among patients attending the outpatient Memory Clinic of a Geriatric Medicine Department in a regional hospital of Singapore was conducted from 2006 till 2009. The inclusion criteria were PWD including AD, VaD, mixed dementia, dementia with Lewy bodies and frontotemporal dementia. Exclusion criteria were: (1) patients with mild cognitive impairment and (2) patients with no caregivers.

\section{Diagnosis of Dementia}

The diagnosis of dementia based on DSM-IV (TR) was established by a multidisciplinary consensus approach on the basis of medical history, clinical examination, relevant blood investigations and brain imaging with either CT scan or MRI. The National Institute of Neurological and Communicative Disorders and Stroke-Alzheimer's Disease and Related Disorders Association (NINCDS-ADRDA) [34] and NINDS-AIREN [35] criteria were used to classify the dementias into $\mathrm{AD}, \mathrm{VaD}$ and $\mathrm{AD}$ with CVD (mixed dementia), respectively. The diagnosis of dementia with Lewy bodies was based on the criteria by McKeith et al. [36]. The clinical diagnosis of frontotemporal dementia was based on the criteria by McKhann et al. [37].

\section{Ethics Approval}

All patients who fulfilled the inclusion criteria gave written informed consent for participation. The research was approved by the Hospital's Ethics Committee and the domainspecific Review Board of the National Healthcare Group. 
Seow et al.: PON1 Gene 192Q/R Polymorphism and Clinical Associations among Older

Singaporean Chinese with Alzheimer's and Mixed Dementia

\section{Data Collection}

Data was collected from reviews of case notes, physical and functional assessments and questionnaire interviews upon first diagnosis by the clinicians and a nurse clinician trained in administering the questionnaires.

\section{Cognitive Status, Neuropsychiatric Symptoms and Functional Status}

Cognitive status was assessed using the Mini-Mental State Examination (MMSE), a validated and widely used measure to determine global cognitive functioning on domains of memory, attention, language, praxis and visual-spatial ability, with summed scores ranging from 0 to 30, higher values denoting better cognitive performance [38]. Global rating scales utilized in the assessment of patients included the Clinical Dementia Rating Scale (CDR) and the Global Deterioration Scale (GDS). The CDR clinically stages the severity of dementia by assessing domains of memory, orientation, judgment and problem-solving, community affairs, home \& hobbies and personal care, with global scores ranging from 0 to $3[39,40]$. The GDS provides caregivers and clinicians with an overview of the stages of cognitive function for those suffering from a primary degenerative dementia such AD [41]. It has 7 stages of which 1-3 are pre-dementia stages and 4-7 are dementia stages. In this study, the patients had a minimum CDR (global) of $\geq 0.5$ and GDS of $\geq 4$.

Neuropsychiatric symptoms were evaluated using the Neuropsychiatric Inventory Questionnaire (NPI-Q), a brief clinical form of the Neuropsychiatric Inventory (NPI) [42], which had previously been validated and highly correlated with NPI and found to be useful in general clinical practice. The NPI-Q is made up of 12 symptom domains derived from the original NPI [43]. Neuropsychiatric symptoms are assessed on a 3-point scale for each symptom domain, and the total NPI severity score represents the sum of the individual symptom scores, it ranges from 0 to 36 . Caregiver distress is anchored on a 0 - to 5 -point scale with the total NPI-Q distress score of $0-60$.

Physical functional status was defined by the Bristol Activities of Daily Living Scale (BADLS), a 20-item carer-rating instrument specifically designed for dementia patients, giving a total score range of 0 to 60 , a lower score indicating better daily function [44]. Functional assessment staging (FAST) was also utilized in evaluating the functional deterioration of $\mathrm{AD}$ and mixed dementia patients during the course of their illness. It is a functional ordinal scale ranging from 1 (no disability) to 7 (highest level of disability) with information based on caregiver input.

\section{Other Biodata}

Other demographic and clinical variables included ethnicity, gender, age, birthplace, education, housing type and a history of diabetes mellitus, hypertension, hyperlipidemia and stroke.

\section{Genotyping}

Whole-blood DNA was extracted using a commercial column (Qiagen-QIAamp DNA Blood mini kit). Real-time polymerase chain reaction was used for genotyping of SNP rs662 (chromosome 7; Applied Biosystems, TaqMan Pre-Designed SNP Genotyping Assay). Multiplex polymerase chain reaction (more than one primer/probe pair per reaction), which allows genotyping of the two possible variants at the single SNP site in a target template sequence, was performed. In each assay, there were two fluorescent dye detectors (one for the wild type, and the other for the mutation). The allelic discrimination assay classified samples as homozygotes (samples with only allele 1 or 2 ) and heterozygotes (samples with both alleles). TaqMan ${ }^{\circledR}$ MGB probe for SNP rs662 (labeled with VIC ${ }^{\circledR}$ dye) was used: (20X)TAAACCCAAATACATCTCCCAGGAT[C/T]GTAAGTAGGGGTCAAGAAAATAGTG 
Table 1. Demographic characteristics of the study population $(\mathrm{n}=186)$

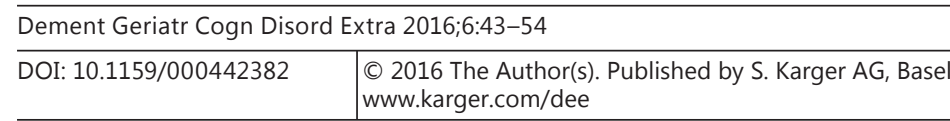

Seow et al.: PON1 Gene 192Q/R Polymorphism and Clinical Associations among Older Singaporean Chinese with Alzheimer's and Mixed Dementia

$\begin{array}{lr}\text { Mean age } \pm \text { SD, years } & 77.3 \pm 7.1 \\ \text { Female gender } & 126(67.7 \%) \\ \text { AD } & 109(58.6 \%) \\ \text { Mixed dementia } & 77(41.4 \%) \\ \text { Diabetes } & 52(28.0 \%) \\ \text { Hypertension } & 121(65.1 \%) \\ \text { Hyperlipidemia } & 88(47.3 \%) \\ \text { Stroke } & 20(10.8 \%)\end{array}$

Based on the Gln (for the $\mathrm{Q}$ allozyme) $\rightarrow$ Arg (for the $\mathrm{R}$ allozyme) substitution at residue 192, three genotypes are derived: QQ, QR and RR.

\section{Statistical Analysis}

Data were analyzed with the independent $t$ test for continuous variables and the $\chi^{2}$ test for categorical variables. The Hardy-Weinberg equilibrium was confirmed for all patients. Allelic frequencies were estimated by the allele counting method. The $\chi^{2}$ test was used (1) to compare genotype and allele frequencies and (2) to compare the differences in prevalence of neuropsychiatric symptoms by the PON1 192Q/R genotypes: RR versus QR, RR versus QQ and $Q R$ versus $Q Q$. Further on, the $\chi^{2}$ test was applied to evaluate the differences in prevalence of neuropsychiatric symptoms in PWD by the PON1 192Q/R allele status (QR or RR, QQ) and among dementia subtypes (AD and mixed dementia). All analyses were conducted using SPSS statistical software version 15.0 (SPSS, Inc., Chicago, Ill., USA). A two-sided p value of $<0.05$ was considered significant.

\section{Results}

\section{Predominant Dementia Subtypes}

$\mathrm{AD}$ and mixed dementia were the predominant dementia subtypes. There were a total of 186 Chinese patients with AD and mixed dementia who had genotyping done. For the other dementia subtypes, there were 7 VaD patients, 1 Parkinson's disease with dementia and 2 dementia with Lewy bodies. As their numbers were too small, these were excluded from the analysis.

Within the AD and mixed dementia group, 109 were AD patients and 77 were mixed dementia patients (mean age 77.3 years, $67.7 \%$ women). More than half had hypertension $(65.1 \%)$ and $47.3 \%$ had hyperlipidemia (table 1). By stage of dementia, 85 patients were at a mild, 90 at a moderate and 11 at a severe stage of dementia.

\section{Distribution of Allele Genotypes}

The distribution of PON1 polymorphisms in the study population is presented in table 2. The genotypes were in Hardy-Weinberg equilibrium and their distribution was not significantly different between the AD patients and the mixed dementia patients $(9 \mathrm{QQ}, 54$ $\mathrm{QR}, 46 \mathrm{RR} ; 9 \mathrm{QQ}, 39 \mathrm{QR}, 29 \mathrm{RR}$, respectively, $\mathrm{p}=0.673$ ). In addition, the presence of at least one R allele (QR or RR) and the presence of at least one Q allele (QR or QQ) were not significantly different between the AD patients and the mixed dementia patients (91.7 and $88.3 \%, p=0.436 ; 57.8$ and $62.3 \%, p=0.534$, respectively). Likewise, the allele distribution was not significantly different between the two groups: the $Q$ allele frequency was $33.0 \%$ in the $\mathrm{AD}$ patients and $37.9 \%$ in the mixed dementia patients, while the R allele frequency was $67.0 \%$ in the $\mathrm{AD}$ patients and $63.1 \%$ in the mixed dementia patients $(\mathrm{p}=0.426)$. The 
Seow et al.: PON1 Gene 192Q/R Polymorphism and Clinical Associations among Older

Singaporean Chinese with Alzheimer's and Mixed Dementia

Table 2. PON1 genotype distribution and allele frequencies in the study population

\begin{tabular}{|c|c|c|c|c|c|c|c|c|c|c|c|}
\hline \multirow[t]{2}{*}{ Group } & \multirow[t]{2}{*}{$\mathrm{n}$} & \multicolumn{3}{|c|}{ Genotype, n (\%) } & \multirow[t]{2}{*}{$\mathrm{p}_{1}$} & \multirow[t]{2}{*}{$\mathrm{p}_{2}$} & \multirow[t]{2}{*}{$\mathrm{p}_{3}$} & \multicolumn{3}{|c|}{ Allele, n (\%) } & \multirow[t]{2}{*}{$\mathrm{p}_{4}$} \\
\hline & & QQ & QR & $\mathrm{RR}$ & & & & Q & $\mathrm{R}$ & $\mathrm{Q} / \mathrm{R}$ & \\
\hline $\mathrm{AD}$ & 109 & $9(8.3)$ & $54(49.5)$ & $46(42.2)$ & 0.673 & 0.436 & 0.534 & $72(33.0)$ & $146(67.0)$ & 0.493 & 0.426 \\
\hline Mixed dementia & 77 & $9(11.7)$ & $39(50.6)$ & $29(37.7)$ & & & & 57 (37.9) & 97 (63.1) & 0.588 & \\
\hline Total & 186 & $18(9.7)$ & $93(50.0)$ & $75(40.3)$ & & & & $129(34.7)$ & $243(65.3)$ & 0.531 & \\
\hline
\end{tabular}

$\mathrm{p}_{1}$ value for $\chi^{2}$ test of differences in PON1 genotype frequencies between AD and mixed dementia patients. $\mathrm{p}_{2}$ value for $\chi^{2}$ test of differences in $(\mathrm{QR}+\mathrm{RR})$ and QQ genotype between $\mathrm{AD}$ and mixed dementia patients. $\mathrm{p}_{3}$ value for $\chi^{2}$ test of differences in $(\mathrm{QR}+\mathrm{QQ})$ and $\mathrm{RR}$ genotype between $\mathrm{AD}$ and mixed dementia patients. $\mathrm{p}_{4}$ value for $\chi^{2}$ test of differences in PON1 allele frequencies between AD and mixed dementia patients.

Table 3. Clinical manifestations and severity of dementia in PWD by PON1 allele status

\begin{tabular}{|c|c|c|c|c|c|c|}
\hline & \multirow{2}{*}{$\begin{array}{l}\text { RR } \\
(n=75)\end{array}$} & \multirow{2}{*}{$\begin{array}{l}Q R \\
(n=93)\end{array}$} & \multirow{2}{*}{$\begin{array}{l}\text { QQ } \\
(n=18)\end{array}$} & \multicolumn{3}{|c|}{$p$ values (from $c^{2}$ test) } \\
\hline & & & & RR vs. QR & RR vs. QQ & QR vs. QQ \\
\hline MMSE score & $15.8 \pm 6.30$ & $15.6 \pm 5.81$ & $16.9 \pm 5.06$ & 0.829 & 0.508 & 0.390 \\
\hline Global CDR score & $1.52 \pm 0.67$ & $1.41 \pm 0.59$ & $1.47 \pm 0.56$ & 0.254 & 0.780 & 0.673 \\
\hline Total CDR score & $8.47 \pm 3.86$ & $8.07 \pm 3.49$ & $7.50 \pm 3.15$ & 0.480 & 0.327 & 0.526 \\
\hline GDS/FAST score & $4.71 \pm 0.90$ & $4.74 \pm 0.85$ & $4.50 \pm 0.62$ & 0.794 & 0.358 & 0.251 \\
\hline NPI-Q (S) score & $8.85 \pm 8.20$ & $8.76 \pm 8.42$ & $4.89 \pm 4.51$ & 0.945 & 0.008 & 0.007 \\
\hline NPI-Q (CD) score & $8.65 \pm 9.89$ & $9.13 \pm 9.36$ & $3.94 \pm 5.22$ & 0.750 & 0.007 & 0.002 \\
\hline BADLS score & $7.29 \pm 10.2$ & $6.24 \pm 7.56$ & $4.50 \pm 6.70$ & 0.455 & 0.271 & 0.366 \\
\hline
\end{tabular}

ratio between $\mathrm{Q}$ and $\mathrm{R}$ allele frequencies was 0.493 in the $\mathrm{AD}$ patients and 0.588 in the mixed dementia patients.

\section{Allele Associations with Cognitive Status, Neuropsychiatric Symptoms and Function}

In the total group, $\mathrm{R}$ allele carriers, compared with non-R allele carriers, showed higher mean NPI-Q (S) scores and NPI-Q (CD) scores (8.80 vs. 4.89, $p=0.004 ; 8.92$ vs. 3.94, $p=0.002$, respectively; tables 3,4$)$. There were no significantly differences in MMSE score $(p=0.426)$, global CDR score $(p=0.928)$, total CDR score $(p=0.407)$, GDS/FAST score $(p=0.283)$ and BADLS score $(\mathrm{p}=0.303)$. The same relationships were examined in patients by AD and mixed dementia subtypes. In the mixed dementia group, the presence of the $\mathrm{R}$ allele was significantly associated with pronouncedly higher mean NPI-Q (S) scores (9.01 vs. 3.11, p = 0.039) and NPI-Q (CD) scores (9.09 vs. 2.33, p = 0.006), as well as with total CDR scores ( 8.57 vs. 5.89 , $\mathrm{p}=0.042$ ), GDS/FAST scores (4.84 vs. 4.11, $\mathrm{p}=0.007$ ) and BADLS scores (6.99 vs. $1.00, \mathrm{p}<$ 0.001 ). In contrast, among patients in the AD subgroup, no significant differences in any of these measures between $\mathrm{R}$ allele carriers and non-carriers were found.

Prevalence of Various Neuropsychiatric Symptoms by the PON1 192Q/R Genotypes and by the Genotype and Dementia Subgroups

For the total group, the prevalence of delusion was significantly higher among patients with the QR genotype than among those with the QQ genotype (47.3 and $22.2 \%$, respectively, 
Seow et al.: PON1 Gene 192Q/R Polymorphism and Clinical Associations among Older Singaporean Chinese with Alzheimer's and Mixed Dementia

Table 4. Clinical manifestations and severity of patients with dementia by PON1 polymorphism status and among dementia subtypes

\begin{tabular}{|c|c|c|c|c|c|c|c|c|c|}
\hline & \multicolumn{3}{|c|}{ Whole sample } & \multicolumn{3}{|l|}{$\mathrm{AD}$} & \multicolumn{3}{|c|}{ Mixed Dementia } \\
\hline & $\begin{array}{l}\text { QR or RR } \\
(n=168)\end{array}$ & $\begin{array}{l}\mathrm{QQ} \\
(\mathrm{n}=18)\end{array}$ & $\begin{array}{l}\mathrm{p} \\
\text { value }\end{array}$ & $\begin{array}{l}Q R \text { or } R R \\
(n=100)\end{array}$ & $\begin{array}{l}Q Q \\
(n=9)\end{array}$ & $\begin{array}{l}\mathrm{p} \\
\text { value }\end{array}$ & $\begin{array}{l}\mathrm{QR} \text { or } \mathrm{RR} \\
(\mathrm{n}=68)\end{array}$ & $\begin{array}{l}Q Q \\
(n=9)\end{array}$ & $\begin{array}{l}\mathrm{p} \\
\text { value }\end{array}$ \\
\hline MMSE score & $15.7 \pm 6.01$ & $16.9 \pm 5.06$ & 0.426 & $15.7 \pm 5.77$ & $14.7 \pm 3.57$ & 0.596 & $15.7 \pm 6.39$ & $19.1 \pm 5.53$ & 0.134 \\
\hline Global CDR score & $1.46 \pm 0.63$ & $1.47 \pm 0.56$ & 0.928 & $1.42 \pm 0.595$ & $1.78 \pm 0.441$ & 0.043 & $1.52 \pm 0.672$ & $1.17 \pm 0.500$ & 0.079 \\
\hline Total CDR score & $8.24 \pm 3.66$ & $7.50 \pm 3.15$ & 0.407 & $8.03 \pm 3.36$ & $9.11 \pm 2.26$ & 0.214 & $8.57 \pm 4.06$ & $5.89 \pm 3.19$ & 0.042 \\
\hline GDS/FAST score & $4.73 \pm 0.87$ & $4.50 \pm 0.62$ & 0.283 & $4.65 \pm 0.809$ & $4.89 \pm 0.333$ & 0.099 & $4.84 \pm 0.940$ & $4.11 \pm 0.601$ & 0.007 \\
\hline NPI-Q (S) score & $8.80 \pm 8.30$ & $4.89 \pm 4.51$ & 0.004 & $8.66 \pm 8.39$ & $6.67 \pm 3.78$ & 0.206 & $9.01 \pm 8.23$ & $3.11 \pm 4.68$ & 0.039 \\
\hline NPI-Q (CD) score & $8.92 \pm 9.58$ & $3.94 \pm 5.22$ & 0.002 & $8.80 \pm 9.69$ & $5.56 \pm 4.90$ & 0.109 & $9.09 \pm 9.47$ & $2.33 \pm 5.29$ & 0.006 \\
\hline BADLS score & $6.71 \pm 8.80$ & $4.50 \pm 6.70$ & 0.303 & $6.52 \pm 8.06$ & $8.00 \pm 7.98$ & 0.598 & $6.99 \pm 9.85$ & $1.00 \pm 2.00$ & $<0.001$ \\
\hline
\end{tabular}

Data are expressed as mean \pm SD.

Table 5. Frequencies of neuropsychiatric symptoms in PWD by PON1 192 Q/R genotypes

\begin{tabular}{|c|c|c|c|c|c|c|}
\hline & \multirow{2}{*}{$\begin{array}{l}\mathrm{RR} \\
(\mathrm{n}=75)\end{array}$} & \multirow{2}{*}{$\begin{array}{l}Q R \\
(n=93)\end{array}$} & \multirow{2}{*}{$\begin{array}{l}\text { QQ } \\
(n=18)\end{array}$} & \multicolumn{3}{|c|}{$\mathrm{p}$ values (from $\mathrm{c}^{2}$ test) } \\
\hline & & & & RR vs. QR & RR vs. QQ & QR vs. QQ \\
\hline Delusions & $26(35.1)$ & $43(47.3)$ & $4(22.2)$ & 0.117 & 0.295 & 0.050 \\
\hline Hallucinations & $15(20.3)$ & $22(24.2)$ & $3(16.7)$ & 0.550 & 1.000 & 0.759 \\
\hline Agitation/aggression & $36(48.6)$ & $50(54.9)$ & $9(50.0)$ & 0.421 & 0.918 & 0.700 \\
\hline Depression/dysphoria & $35(47.3)$ & $37(40.7)$ & $6(33.3)$ & 0.393 & 0.285 & 0.561 \\
\hline Anxiety & $29(39.2)$ & $40(44.0)$ & $5(27.8)$ & 0.537 & 0.368 & 0.203 \\
\hline Elation/euphoria & $9(12.2)$ & $8(8.8)$ & $2(11.1)$ & 0.479 & 1.000 & 0.669 \\
\hline Apathy/indifference & $39(52.7)$ & $51(56.0)$ & $9(50.0)$ & 0.668 & 0.837 & 0.638 \\
\hline Disinhibition & $30(40.5)$ & $31(34.1)$ & $5(27.8)$ & 0.392 & 0.317 & 0.604 \\
\hline Irritability/liability & $34(45.9)$ & $40(44.0)$ & 7 (38.9) & 0.798 & 0.589 & 0.692 \\
\hline Aberrant motor behavior & $22(29.7)$ & $32(35.2)$ & $7(38.9)$ & 0.459 & 0.453 & 0.763 \\
\hline Nighttime behaviors & $38(51.4)$ & $41(45.1)$ & $6(33.3)$ & 0.421 & 0.170 & 0.359 \\
\hline Appetite/eating change & $23(31.1)$ & $36(39.6)$ & $4(22.2)$ & 0.258 & 0.459 & 0.163 \\
\hline
\end{tabular}

Figures are numbers with percentages in parentheses.

$\mathrm{p}=0.050$; table 5). Within the mixed dementia subgroup, R allele carriers, compared with non-R allele carriers, showed a significantly lower prevalence of elation/euphoria (11.9 vs. $100.0 \%, \mathrm{p}<0.001$ ) and a higher prevalence of nighttime behaviors ( $49.3 \mathrm{vs.} 11.1 \%, \mathrm{p}=0.037$; table 6).

\section{Discussion}

This study provides unique pilot data on the PON1 192Q/R polymorphism and its distribution among older Chinese patients with AD and mixed dementia in Singapore. We found that $67 \%$ of the AD patients and $63.1 \%$ of the patients with mixed dementia carried at least one $\mathrm{R}$ allele. In contrast to populations of European descent where the $\mathrm{Q}$ allele is predominant, the R allele is more frequent among Chinese PWD in Singapore. This finding is similar to that in Japan [29]. In a study on a mainland Chinese Han ethnic population, He et al. [23] reported that the PON1 R allele frequencies in AD patients and healthy controls were 0.607 
Seow et al.: PON1 Gene 192Q/R Polymorphism and Clinical Associations among Older

Singaporean Chinese with Alzheimer's and Mixed Dementia

Table 6. Frequencies of neuropsychiatric symptoms in PWD by PON1 192 Q/R allele status and among dementia subtypes

\begin{tabular}{|c|c|c|c|c|c|c|c|c|c|}
\hline & \multicolumn{3}{|c|}{ Whole sample } & \multicolumn{3}{|l|}{$\mathrm{AD}$} & \multicolumn{3}{|c|}{ Mixed dementia } \\
\hline & $\begin{array}{l}\text { QR or RR } \\
(n=168)\end{array}$ & $\begin{array}{l}\text { QQ } \\
(n=18)\end{array}$ & $\begin{array}{l}\mathrm{p} \\
\text { value }\end{array}$ & $\begin{array}{l}\text { QR or RR } \\
(n=100)\end{array}$ & $\begin{array}{l}Q Q \\
(n=9)\end{array}$ & $\begin{array}{l}\mathrm{p} \\
\text { value }\end{array}$ & $\begin{array}{l}\text { QR or RR } \\
(n=68)\end{array}$ & $\begin{array}{l}Q Q \\
(n=9)\end{array}$ & $\begin{array}{l}\mathrm{p} \\
\text { value }\end{array}$ \\
\hline Delusions & 69 (41.8) & $4(22.2)$ & 0.107 & $41(41.8)$ & $2(22.2)$ & 0.309 & $28(41.8)$ & $2(22.2)$ & 0.469 \\
\hline Hallucinations & $37(22.4)$ & $3(16.7)$ & 0.767 & $23(23.5)$ & $1(11.1)$ & 0.680 & $14(20.9)$ & $2(22.2)$ & 1.000 \\
\hline Agitation/aggression & $86(52.1)$ & $9(50.0)$ & 0.864 & $50(51.0)$ & $5(55.6)$ & 1.000 & $36(53.7)$ & $4(44.4)$ & 0.728 \\
\hline Depression/dysphoria & $72(43.6)$ & $6(33.3)$ & 0.401 & $42(42.9)$ & $2(22.2)$ & 0.302 & $30(44.8)$ & $4(44.4)$ & 1.000 \\
\hline Anxiety & $69(41.8)$ & $5(27.8)$ & 0.249 & $44(44.9)$ & $1(11.1)$ & 0.076 & $25(37.3)$ & $4(44.4)$ & 0.725 \\
\hline Elation/euphoria & $17(10.3)$ & $2(11.1)$ & 1.000 & $9(9.2)$ & $2(22.2)$ & 0.232 & 8 (11.9) & $9(100)$ & $<0.001$ \\
\hline Apathy/indifference & $90(54.5)$ & $9(50.0)$ & 0.713 & $53(54.1)$ & $6(66.7)$ & 0.728 & $37(55.2)$ & $3(33.3)$ & 0.294 \\
\hline Disinhibition & $61(37.0)$ & $5(27.8)$ & 0.441 & $39(39.8)$ & $3(33.3)$ & 1.000 & $22(32.8)$ & $2(22.2)$ & 0.711 \\
\hline Irritability/liability & $74(44.8)$ & $7(38.9)$ & 0.629 & $41(41.8)$ & $3(33.3)$ & 0.734 & $33(49.3)$ & $4(44.4)$ & 1.000 \\
\hline Aberrant motor behavior & $54(32.7)$ & 7 (38.9) & 0.598 & $33(33.7)$ & $5(55.6)$ & 0.275 & $21(31.3)$ & $2(22.2)$ & 0.715 \\
\hline Nighttime behaviors & 79 (47.9) & $6(33.3)$ & 0.240 & $46(46.9)$ & $54(55.6)$ & 0.734 & $33(49.3)$ & $1(11.1)$ & 0.037 \\
\hline Appetite/eating change & $59(35.8)$ & $4(22.2)$ & 0.251 & $38(38.8)$ & $3(33.3)$ & 1.000 & $21(31.3)$ & $1(11.1)$ & 0.271 \\
\hline
\end{tabular}

Figures are numbers with percentages in parentheses.

and 0.647 , respectively. Our study confirms the predominance of the $\mathrm{R}$ allele amongst the Chinese with concordant frequencies between the Han and Singaporean Chinese dementia subpopulations of AD and mixed dementia. It also adds to the findings of previous studies which suggest ethnic variations in the distribution of $\mathrm{R}$ and $\mathrm{Q}$ alleles, which in turn confer different $\mathrm{AD}$ risk associations in different ethnic populations.

The role of PON1 in AD and non-AD dementia has been explored in various studies. Helbecque et al. [32] studied both $\mathrm{AD}$ and non-AD demented patients (VaD and mixed dementia) and showed that the R allele was an independent risk factor for non-AD dementia. Within the PON1 gene itself, the differences in importance between the promoter and coding regions of PON1 on dementia have been clearly defined. In a more recent paper by Bednarska-Makaruk et al. [45], the significant association of PON1 activity with PON1 $-108 \mathrm{C}>\mathrm{T}$ and the PON1 Q192R polymorphisms was confirmed in a multivariate regression analysis, and the PON1 -108T allele had an effect on PON1 activity compared to the PON1 192R allele. This study also showed that PON1 activity was significantly lower in demented patients when compared with controls, particularly in AD and mixed dementia patients [45].

At the pathophysiological level, recent research has shown the contributing role of the PON1 192Q/R polymorphism towards the pathogenesis and risk of AD. While research has shown that PON1 gene polymorphisms may be limited in the pathogenesis of $A D$, a recent paper by Erlich et al. [46] (in 2010) showed that while the mechanisms by which PON1 influences $\mathrm{AD}$ is unknown, the risk-conferring effect of PON1 on AD is nevertheless significant. By measuring the arylesterase and lactonase activity, the odds of AD (adjusted for age, gender and ethnicity) increased $20 \%$ for each standard deviation decrease in arylesterase or lactonase activity. This study also showed association signals with activity across all 3 PON genes (i.e. PON1, PON2 and PON3). Haplotypes including SNPs spanning the PON genes were noted to be more significant than haplotypes comprising SNPs from 1 gene with significant interactions between SNP pairs located across the PON cluster. It concluded that low serum PON activity is a risk factor for $\mathrm{AD}$ with the further explanation that multiple variants in PON influence serum PON activity and their effects may be synergistic. 
Seow et al.: PON1 Gene 192Q/R Polymorphism and Clinical Associations among Older

Singaporean Chinese with Alzheimer's and Mixed Dementia

A recent study also demonstrated the positive correlation of PON1 activity with serum insulin level and homeostatic model assessment index (HOMA-IR) [47]. In another paper by Leduc and Poirier [19], the M55M genotype was significantly associated with AD risk, whereas PON1 192Q/R was not. In addition, the PON1 192Q/R polymorphism had no effect on choline acetyltransferase activity and nicotinic receptor density in the temporal cortex of AD patients compared to the met allele. However, it was found that AD subjects carrying at least one Arg allele at the Q192 locus had significantly lower A $\beta 42 / A \beta 40$ ratios relative to AD Q192Q homozygous patients. These results highlight the role of PON1 as an anti-oxidant HDL-associated enzyme in lipoprotein complexes which function as scavengers of normally secreted extracellular lipophilic/ nonaggregated $A \beta$ peptides in vivo.

The findings of this current study which suggest that Singaporean Chinese patients with mixed dementia (in particular those carrying the R allele) presented with greater numbers of neuropsychiatric symptoms and at more severe stages of dementia and AD invites interesting considerations. Low serum levels of PON1 activity were reported in one study of AD patients compared to $\mathrm{VaD}$ [30]. The $\mathrm{R}$ allele has been associated with an increased risk of stroke in Asians [48-51].

The presence of cerebrovascular disease in $\mathrm{AD}$ patients resulting in neuropsychiatric symptoms has been studied. A previous paper established that cerebral white matter disease is independently associated with behavioral and psychological symptoms of dementia in AD in Singapore [52]. Other studies, e.g. the Cache County Study in the USA, reflect the same association $[53,54]$.

Regarding the role of PON1 in enhancing the risk of cerebrovascular disease which in turn leads to greater disease burden in AD patients in the form of neuropsychiatric symptoms and severity, this has not been examined before. PON1 inhibits LDL oxidation, which in turn drives HDL to exert its anti-atherogenic activity. It has been established that different PON polymorphisms, which affect lipid oxidation activity, are risk factors for different neurological diseases $[26,55]$. Another study has postulated that enhanced lipid peroxides target specific cells in different populations of patients, e.g. endothelial cells in stroke patients and cortical neurons in AD patients [56]. We hypothesize that the PON1 R allele does play a role in increasing cerebrovascular disease burden in $\mathrm{AD}$ patients and in turn neuropsychiatric symptoms, the mechanisms of which need to be further explored and understood.

The study has several limitations. (1) The sample size of the patient groups with the PON1 QQ genotype was small (9 QQ in the AD group and 9 QQ in the mixed dementia group). Although highly significant, the use of multiple testing could generate spurious results by chance, hence, the results suggesting an effect of the PON1 192Q/R polymorphism on neuropsychiatric symptoms would have to be replicated in studies with larger numbers of the QQ genotype. (2) The effect of the APOE status on disease severity and neuropsychiatric symptoms in $\mathrm{AD}$ patients has been well-documented. Subanalyses (data not shown) did not demonstrate an association of $A P O E$ with the PON1 status, or a confounding effect on dementia severity and neuropsychiatric symptoms. However, an interaction effect of APOE and PON1 is still possible and cannot be excluded. (3) Inadequate control of confounding by vascular and other risk factors (including age, smoking, lifestyle and education status) may also have contributed to the findings. (4) The influence of other polymorphisms in the PON1 gene on AD and mixed dementia could not be excluded. Other PON1 polymorphisms including pL55M and -108C > T have been shown to play a significant role in AD risk and pathogenesis. (5) The number of VaD patients was too small to examine the role of the PON1 Q/R genotype on this dementia subtype. (6) While the assessments were conducted by an experienced geriatrician and a trained nurse, it is still possible that there was an element of human subjectivity during the assessments of cognitive status and neuropsychiatric symptoms. This could potentially reduce the credibility of the results. (7) Analyses into possible associations of allele and 
Seow et al.: PON1 Gene 192Q/R Polymorphism and Clinical Associations among Older

Singaporean Chinese with Alzheimer's and Mixed Dementia

genotype frequencies with diabetes mellitus, hypertension, hyperlipidemia and stroke were not conducted. (8) Associations of the R allele status with age of onset, clinical course and stage of dementia together with neuroimaging evidence of cerebrovascular disease were not studied.

\section{Conclusion}

This study provides significant pilot data on the PON1 192Q/R polymorphism and its prevalence amongst Singaporean Chinese patients with AD and mixed dementia which has hitherto not been demonstrated locally. It concurs with previous studies demonstrating the predominance of the $\mathrm{R}$ allele amongst Chinese dementia patients. It also provides interesting data on the possible association of the R allele with disease severity, functional status and manifestation in the mixed dementia subgroup. These findings should be replicated in other studies. Future study directions include: (1) a comparison of the distribution of the PON1 192Q/R polymorphism among PWD and controls in Singapore; this would enable us to assess the postulated protective effect of the R genotype against AD, (2) association studies between the different PON gene polymorphisms (PON1, PON2 and PON3), vascular risk factors (including lifestyle risk factors e.g. smoking) and dementia across different ethnic groups and (3) association studies of PON1 polymorphisms with neuroimaging markers of cerebrovascular disease and $\mathrm{AD}$ in light of the high burden of cerebrovascular white matter disease in the local population and its association with behavioral and psychological symptoms of dementia in AD [57]. These will help further our understanding of the association and clinical significance of PON and dementia in Singapore.

\section{Acknowledgements}

This study was funded by a National Medical Research Council (Singapore) Enabling Grant awarded in 2007. Protocol No. A07271.

\section{Disclosure Statement}

There is no conflict of interest.

\section{References}

1 Sahadevan S, Saw SM, Gao W, Tan LC, Chin JJ, Hong CY, Venketasubranmanian N: Ethnic differences in Singapore's dementia prevalence: the stroke, Parkinson's disease, epilepsy, and dementia in Singapore study. J Am Geriatr Soc 2008:56:2061-2068.

2 Dong Y, Gan DZ, Tay SZ, Koay WI, Collinson SL, Hilal S, Venketasubramanian N, Chen C: Patterns of neuropsychological impairment in Alzheimer's disease and mixed dementia. J Neurol Sci 2013;333:5-8.

-3 Lyketsos CG, Lopez O, Jones B, Fitzpatrick AL, Breitner J, DeKosky S: Prevalence of neuropsychiatric symptoms in dementia and mild cognitive impairment: results from the cardiovascular health study. JAMA 2002;288: 1475-1483.

4 Lyketsos CG, Steinberg M, Tschanz JT, Norton MC, Steffens DC, Breitner JC: Mental and behavioural disturbances in dementia: findings from the Cache County Study on Memory in Aging. Am J Psychiatry 2000;157: 708-714.

5 Clendenning JB, Humbert R, Green ED, Wood C, Traver D, Furlong CE: Structural organization of the human PON1 gene. Genomics 1996;35:586-589.

-6 Mackness M, Durrington P, Mackness B: Paraoxonase 1 activity, concentration and genotype in cardiovascular disease. Curr Opin Lipidol 2004;15:399-404. 
-7 Roest M, Jansen AC, Barendrecht A, Leus FR, Kastelein JJ, Voorbij HA: Variation at the paraoxonase gene locus contributes to carotid arterial wall thickness in subjects with familial hypercholesterolemia. Clin Biochem 2005;38:123-127.

-8 Voetsch B, Benke KS, Panhuysen CI, Damasceno BP, Loscalzo J: The combined effect of paraoxonase promoter and coding region polymorphisms on the risk of arterial ischemic stroke among young adults. Arch Neurol 2004:61;351-356.

-9 Wheeler JG, Keavney BD, Watkins H, Collins R, Danesh J: Four paraoxonase gene polymorphisms in 11212 cases of coronary heart disease and 12786 controls: meta-analysis of 43 studies. Lancet 2004;63:689-695.

$>10$ Sanghera DK, Aston CE, Saha N, Kamboh MI: DNA polymorphisms in two paraoxonase genes (PON1 and PON2) are associated with the risk of coronary heart disease. Am J Hum Genet 1998;62:36-44.

$\checkmark 11$ Jarvik GP, Rozek LS, Brophy VH, Hatsukami TS, Richter RJ, Schellenberg GD, Furlong CE: Paraoxonase (PON1) phenotype is a better predictor of vascular disease than is PON1(192) or PON1(55) genotype. Arterioscle Thromb Vasc Biol 2000;20:2441-2447.

-12 Chen Q, Reis SE, Kammerer CM, McNamara DM, Holubkov R, Sharaf BL, Sopko G, Pauly DF, Merz CN, Kamboh MI; WISE Study Group: Association between the severity of angiographic coronary artery disease and paraoxonase gene polymorphisms in the National Heart, Lung, and Blood Institute-sponsored Women's Ischemia Syndrome Evaluation (WISE) study. Am J Hum Genet 2003;72:13-22.

13 Précourt LP, Amre D, Denis MC, Lavoie JC, Delvin E, Seidman E, Levy E: The three-gene paraoxonase family: physiologic roles, actions and regulation. Atherosclerosis 2011;214:20-36.

14 Lescai F, Marchegiani F, Franceschi C: PON1 is a longevity gene: results of a meta-analysis. Aging Res Rev 2009; 8;277-284.

15 Blatter MC, James RW, Messmer S, Barja F, Pometta D: Identification of a distinct human high-density lipoprotein subspecies defined by a lipoprotein-associated protein, K-45: identity of K-45 with paraoxonase. Eur J Biochem 1993;211:871-879.

16 Fong CS, Cheng CW, Wu RM: Pesticides exposure and genetic polymorphism of paraoxonase in the susceptibility of Parkinson's disease. Acta Neurol Taiwan 2005;14:55-60.

-17 Kondo I, Yamamoto M: Genetic polymorphism of paraoxonase 1 (PON1) and susceptibility to Parkinson's disease. Brain Res 1998;806:271-273.

18 Cellini E, Tedde A, Bagnoli S, Nacmias B, Piacentini S, Bessi V, Bracco L, Sorbi S: Association analysis of the paraoxonase-1 gene with Alzheimer's disease. Neurosci Lett 2006;408:199-202.

19 Leduc V, Poirier J: Polymorphisms at the paraoxonase 1 L55M and Q192R loci affect the pathophysiology of Alzheimer's disease: emphasis on the cholinergic system and beta-amyloid levels. Neurodegener Dis 2008;5: 225-227.

20 Humbert R, Adler DA, Disteche CM, Hassett C, Omiecinski CJ, Furlong CE: The molecular basis of the human serum paraoxonase activity polymorphism. Nat Genet 1993;3:73-76.

-21 Pola R, Flex A, Ciaburri M, Rovella E, Valiani A, Reali G, Silveri MC, Bernabei R: Responsiveness to cholinesterase inhibitors in Alzheimer's disease: a possible role for the 192 Q/R polymorphism of the PON-1 gene. Neurosci Lett 2005;382:338-341.

22 Pi Y, Zhang L, Chang K, Li B, Guo L, Fang C, Gao C, Wang J, Xiang J, Li J: Lack of an association between Paraoxonase 1 gene polymorphisms (Q192R, L55M) and Alzheimer's disease: a meta-analysis. Neurosci Lett 2012; 523:174-179.

23 He XM, Zhang ZX, Zhang JW, Zhou YT, Tang MN, Wu CB, Hong Z: Gln192Arg polymorphism in paraoxonase 1 gene is associated with Alzheimer disease in a Chinese Han ethnic population. Chin Med J (Engl) 2006;119: 1204-1209.

24 Scacchi R, Gambina G, Martini MC, Broggio E, Vilardo T, Corbo RM: Different pattern of association of paraoxonase Gln192->Arg polymorphism with sporadic late-onset Alzheimer's disease and coronary artery disease. Neurosci Lett 2003;339:17-20.

25 Chapuis J, Boscher M, Bensemain F, Cottel D, Amouyel P, Lambert JC: Association study of the paraoxonase 1 gene with the risk of developing Alzheimer's disease. Neurobiol Aging 2009;30:152-156.

-26 Erlich PM, Lunetta KL, Cupples LA, Huyck M, Green RC, Baldwin CT, Farrer LA; MIRAGE Study Group: Polymorphisms in the PON gene cluster are associated with Alzheimer disease. Hum Mol Genet 2006;15:77-85.

27 Pola R, Gaetani E, Flex A, Gerardino L, Aloi F, Flore R, Serricchio M, Pola P, Bernabei R: Lack of association between Alzheimer's disease and Gln-Arg 192 Q/R polymorphism of the PON-1 gene in an Italian population. Dement Geriatr Cogn Disord 2003;15:88-91.

28 Shi JJ, Zhang SZ, Ma C, Tang MN, Liu XH, Wang YC, Han HY, Guo YB, Feng RM, Miao GD: Gln192Arg polymorphism of the paraoxonase-1 gene is not associated with Alzheimer's disease in Chinese. Di Yi Jun Yi Da Xue Xue Bao 2004;24:371-374.

29 Sodeyama N, Yamada M, Itoh Y, Suematsu N, Matsushita M, Otomo E, Mizusawa H: No association of paraoxonase gene polymorphism with atherosclerosis or Alzheimer's Disease. Neurology 1999;53:1146-1148.

30 Paragh G, Balla P, Katona E, Seres I, Egerhazi A, Degrell I: Serum paraoxonase activity changes in patients with Alzheimer's disease and vascular dementia. Eur Arch Psychiatry Clin Neurosci 2002;252:63-67.

-31 Dantoine TF, Drouet M, Debord J, Merle L, Cogne M, Charmes JP: Paraoxonase 1 192/55 gene polymorphisms in Alzheimer's disease. Ann NY Acad Sci 2002;977:239-244.

-32 Helbecque N, Cottel D, Codron V, Berr C, Amouyel P: Paraoxonase 1 gene polymorphisms and dementia in humans. Neurosci Lett 2004;358:41-44. 
-33 Zuliani G, Ble' A, Zanca R, Munari MR, Zurlo A, Vavalle C, Atti AR, Fellin R: Genetic polymorphisms in older subjects with vascular or Alzheimer's dementia. Acta Neurol Scand 2001;103:304-308.

-34 McKhann G, Drachman D, Folstein M, Katzman R, Price D, Stadlan EM: Clinical diagnosis of Alzheimer's disease: report of the NINCDS-ADRDA Work Group under the auspices of Department of Health and Human Services Task Force on Alzheimer's disease. Neurology 1984;34:939-944.

-35 Roman GC, Tatemichi TK, Erkinjuntti T, et al: Vascular dementia: diagnostic criteria for research studies. Report of the NINDS-AIREN International Workshop. Neurology 1993;43:250-260.

36 McKeith IG, Dickson DW, Lowe J, et al: Diagnosis and management of dementia with Lewy bodies: third report of the DLB Consortium. Neurology 2005;65:1863-1872.

-37 McKhann GM, Albert MS, Grossman M, Miller B, Dickson D, Trojanowski JQ; Work Group on Frontotemporal Dementia and Pick's Disease: Clinical and pathological diagnosis of frontotemporal dementia: report of the Work Group on Frontotemporal Dementia and Pick's Disease. Arch Neurol 2001;58:1803-1809.

-38 Folstein MF, Folstein SE, McHugh PR: Mini-Mental State: a practical method for grading the cognitive state of patients for the clinician. J Psychiatr Res 1975;12:189-198.

39 Berg L: Clinical dementia rating (letter). Br J Psychiatry 1982;145:339.

40 Hughes CP, Berg L, Danziger WL, Coben LA, Martin RL: A new clinical scale for the staging of dementia. Br J Psychiatry 1982;140:566-572.

41 Reisberg B, Ferris SH, de Leon MJ, Crook T: Global Deterioration Scale (GDS). Psychopharm Bull 1988;24: 661-663.

-42 Cummings JL: The Neuropsychiatric Inventory: assessing psychopathology in dementia patients. Neurology 1997;48:S10-S16.

43 Kaufer DI, Cummings JL, Ketchel P, Smith V, MacMillan A, Shelley T, Lopez OL, DeKosky ST: Validation of the NPI-Q, a brief clinical form of the neuropsychiatric inventory. J Neuropsy Clin Neurosci 2000;12:233-239.

44 Bucks RS, Ashworth DL, Wilcock GK, Siegfried K: Assessment of activities of daily living in dementia: development of the Bristol Activities of Daily Living Scale. Age Ageing 1996;25:113-120.

-45 Bednarska-Makaruk ME, Krzywkowski T, Graban A, Lipczynska-Lojkowska W, Bochynska A, Rodo M, Wehr H, Ryqlewicz DK: Paraoxonase 1 (PON1) gene -108C>T and p.Q192R polymorphisms and arylesterase activity of the enzyme in patients with dementia. Folia Neuropathol 2013;51:111-119.

-46 Erlich PM, Lunetta KL, Cupples LA, Abraham CR, Green RC, Baldwin CT, Farrer LA: Serum paraoxonase activity is associated with variants in the PON gene cluster and risk of Alzheimer disease. Neurobiol Aging 2012;33: 1015.e7-e23.

47 Benaraska-Makaruk M, Graba A, Lipczynska-Lojkowska W, Bochynska A, Rodo M, Krzywkowski T, Rygleicz D, Wehr H: Positive correlation of paraoxonase 1 (PON1) activity with serum insulin level and HOMA-IR I dementia: a possible advantageous role of PON1 in dementia development. J Neurol Sci 2013;324:172-175.

-48 Imai Y, Morita H, Kurihara H, Sugiyama T, Kato N, Ebihara A, Hamada C, Kurihara Y, Shindo T, Oh-hashi Y, Yazaki Y: Evidence for association between paraoxonase gene polymorphisms and atherosclerotic disease. Atherosclerosis 2000;149:435-442.

49 Baum L, Ng HK, Woo KS, Tomlinson B, Rainer TH, Chen X, Cheung WS, Chan DK, Thomas GN, Tong CS, Wong KS: Paraoxonase1 gene Q192R polymorphism affects stroke and myocardial infarction risk. Clin Biochem 2006;39:191-195.

-50 Ranade K, Kirchgessner TG, Iakoubova OA, Devlin JJ, Del Monte T, Vishnupad P, Hui L, Tsuchihashi Z, Sacks FM, Sabatine MS, Braunwald E, White TJ, Shaw PM, Dracopoli NC: Evaluation of the paraoxonases as candidate genes for stroke: Gln192Arg polymorphism in the paraoxonase 1 gene is associated with increased risk of stroke. Stroke 2005;36:2346-2350.

51 Voetsch B, Benke KS, Damasceno BP, Siqueira LH, Loscalzo J: Paraoxonase 192 Gln $\rightarrow$ Arg polymorphism: an independent risk factor for nonfatal arterial ischemic stroke among young adults. Stroke 2002;33:1459-1464.

52 Kandiah N, Chander R, Zhang A, Yee CC: Cerebral white matter disease is independently associated with BPSD in Alzheimer's disease. J Neurol Sci 2014;337:162-166.

-53 Treiber KA, Lyketsos CG, Corcoran C, Steinberg M, Norton M, Green RC, Rabins P, Stein DM, Welsh-Bohmer KA, Breitner JC, Tschanz JT: Vascular factors and risk for neuropsychiatric symptoms in Alzheimer's disease: the Cache County Study. Int Psychogeriatr 2008;20:538-553.

54 Palmqvist S, Sarwari A, Wattmo C, Bronge L, Zhang Y, Wahlund LO, Nägga K: Association between subcortical lesions and behavioral and psychological symptoms in patients with Alzheimer's disease. Dement Geriatr Cogn Disord 2001;32:417-423.

55 Rosenblat M, Hayek T, Hussein K, Aviram M: Decreased macrophage paraoxonase 2 expression in patients with hypercholesterolemia is the result of their increased cellular cholesterol content: effect of atorvastatin therapy. Arterioscler Thromb Vasc Biol 2004;24:175-180.

-56 Slowik A, Wloch D, Szermer P, Wolkow P, Malecki M, Pera J, Turaj W, Dziedzic T, Klimkowicz-Mrowiec A, Kopec G, Figlewicz DA, Szczudlik A: Paraoxonase 2 gene C311S polymorphism is associated with a risk of large vessel disease stroke in a Polish population. Cerebrovasc Dis 2007;23:395-400.

57 Xu X, Hilal S, Collinson SL, Chong EJ, Ikram MK, Venketasubramanian N, Chen CL: Association of magnetic resonance imaging markers of cerebrovascular disease burden and cognition. Stroke 2015;46:2808-2814. 